\title{
Mechanochemical Activation on the Preparation of $\beta$-Eucryptite from Powder Mixture of Pyrophyllite, Gibbsite and Lithium Carbonate
}

\author{
Wantae Kim ${ }^{1}$, Kwanho Kim ${ }^{1}$, Hoon Lee ${ }^{1}$, Minchul $\mathrm{Shin}^{2}$ and Sangbae Kim ${ }^{1, *}$ \\ ${ }^{1}$ Korea Institute of Geoscience and Mineral Resources, 124 Gwahang-ro, Yuseong-gu, Daejeon 305-350, Korea \\ ${ }^{2}$ Chonnam National University, 77 Yongbong-ro, Buk-gu, Gwangju 500-757, Korea
}

$\beta$-eucryptite $\left(\mathrm{Li}_{2} \mathrm{O} \cdot \mathrm{Al}_{2} \mathrm{O}_{3} \cdot 2 \mathrm{SiO}_{2}\right)$ was prepared by mechanochemical activation followed by calcination of the powder mixture containing pyrophyllite, gibbsite and lithium carbonate. XRD and FT-IR results showed that the crystallization of $\beta$-eucryptite occurred from the milled mixture by calcination. Dry milling using a planetary mill promoted the amorphization of the mixture. The crystallization of $\beta$-eucryptite increased with increment of milling time and calcination temperature. Trace amount of undesired phases such as cristobalite and quartz disappeared completely at $950^{\circ} \mathrm{C}$ in the mixture milled for $120 \mathrm{~min}$. The thermal expansion behavior characteristics were found to be strongly influenced by the milling time of the constituent powder mixture and calcination temperature. [doi:10.2320/matertrans.M2012332]

(Received October 4, 2012; Accepted December 12, 2012; Published January 25, 2013)

Keywords: $\beta$-eucryptite, mechanochemical activation, crystallization, thermal expansion, pyrophyllite

\section{Introduction}

Lithium aluminum silicate (LAS) glass ceramics, one of the most important glass ceramic system, has been extensively investigated because of its very low or even negative thermal expansion properties as well as high chemical durability. ${ }^{1,2)}$ They are used in industry as furnace materials and as gas turbine heat exchangers where the dimensional stability and ability to resist thermal shock are necessary. Currently the manufacture of some cookwares, electronic devices, telescope mirror blanks, ring-laser gyroscopes and optically stable platforms are other wide spread applications of LAS glass ceramics. ${ }^{3)}$

The important crystalline phases in LAS glass ceramics are $\beta$-eucryptite $\left(\mathrm{Li}_{2} \mathrm{O} \cdot \mathrm{Al}_{2} \mathrm{O}_{3} \cdot 2 \mathrm{SiO}_{2}\right)$ and $\beta$-spodumene $\left(\mathrm{Li}_{2} \mathrm{O}\right.$. $\mathrm{Al}_{2} \mathrm{O}_{3} \cdot 4 \mathrm{SiO}_{2}$ ). Conventionally, these LAS glass ceramics have been prepared by the recrystallization of solidified glass melting. ${ }^{4,5)}$ However, there arises a problem during sintering without proper aids such as $\mathrm{TiO}_{2}, \mathrm{~F}$ and those containing $\mathrm{ZrO}_{2}, \mathrm{P}_{2} \mathrm{O}_{5}$ and $\mathrm{TiO}_{2}$. The incorporation of sintering aids results in a large thermal expansion coefficient. The other problem is the high sintering temperature of the melting glass. Some oxides such as $\mathrm{ZnO}, \mathrm{CaO}, \mathrm{Na}_{2} \mathrm{O}$ and $\mathrm{K}_{2} \mathrm{O}$ were added in order to lower the sintering temperature. ${ }^{6-8)}$ The addition of these oxides can cause the formation of undesirable phases resulting in undesirable effect on the thermal expansion properties. Furthermore, more complicated processing parameters must be undertaken in order to eliminate the influence of these phases. Therefore, the preparation of homogeneous powder of LAS glass ceramic system is becoming an important technical objective.

In the present paper, LAS glass ceramic in $\beta$-eucryptite form was prepared by mechanochemical activation followed by calcination of the powder mixture containing pyrophyllite $\left(\mathrm{Al}_{2} \mathrm{O}_{3} \cdot 4 \mathrm{SiO}_{2} \cdot \mathrm{H}_{2} \mathrm{O}\right)$, gibbsite $\left(\mathrm{Al}_{2} \mathrm{O}_{3} \cdot 3 \mathrm{H}_{2} \mathrm{O}\right)$ and lithium carbonate $\left(\mathrm{Li}_{2} \mathrm{CO}_{3}\right)$. Although mechanochemical effects involving mechanical activation and/or room temperature solid-state reaction between the particles have been widely

${ }^{*}$ Corresponding author, E-mail: sbkim@kigam.re.kr reported, very little information is available on the application of intensive dry milling operation for the preparation of LAS glass ceramics. The main purpose of this work is to provide information on a simple method to prepare $\beta$ eucryptite directly from the constituent powder substances. The crystallization and thermal expansion behavior of $\beta$ eucryptite prepared according to the milling time and calcination temperature were characterized by XRD, TGDTA, FT-IR, SEM and dilatometry.

\section{Experimental}

The powder mixture with molar ratio of $\mathrm{Li}: \mathrm{Al}$ : Si keeping at $1: 1: 1$ corresponding to $\beta$-eucryptite phase was prepared by mixing pyrophyllite, gibbsite and lithium carbonate as starting materials. The pyrophyllite obtained from Nowha mine of Korea in lumpy form was first crushed in a stainless steel stamp mill and then sieved it to pass a 200 mesh $(75 \mu \mathrm{m})$ screen. The main impurity mineral of the pyrophyllite sample was revealed as quartz by preliminary XRD analysis. The gibbsite, produced from KC Co. Ltd., Korea, of which 95 mass\% was less than $50 \mu \mathrm{m}$, and reagent grade lithium carbonate supplied from Junsei Chemical Co. Ltd., Japan were used. The chemical compositions of these starting materials are shown in Table 1.

A planetary ball mill, Fritsch Palverisette-7, Germany, was used to mill the starting mixture at approximately $650 \mathrm{rpm}$ under atmospheric condition. Five grams of the mixture was put in a zirconia pot of $45 \mathrm{~cm}^{3}$ inner volume with seven zirconia balls of $15 \mathrm{~mm}$ diameter and milled for different periods of times. The duration of milling was varied from 15 to $120 \mathrm{~min}$. The milling was suspended for $10 \mathrm{~min}$ after every 15-min milling to avoid excess temperature increase inside the mill pots during prolonged milling. The milled mixture was then calcined at 750,850 and $950^{\circ} \mathrm{C}$ for $1 \mathrm{~h}$ in atmospheric condition at a heating rate of $10^{\circ} \mathrm{C} / \mathrm{min}$.

The evolution of crystalline phases of powders during milling and calcination was investigated by X-ray diffraction analysis (RINT-2000, Rigaku). The thermal analysis of milled powders was conducted using a TG-DTA analyzer 
Table 1 Chemical composition of the starting materials.

\begin{tabular}{|c|c|c|c|c|c|c|c|c|c|}
\hline \multirow{2}{*}{ Materials } & \multicolumn{9}{|c|}{ Chemical composition (mass $\%$ ) } \\
\hline & $\mathrm{SiO}_{2}$ & $\mathrm{Al}_{2} \mathrm{O}_{3}$ & $\mathrm{Fe}_{2} \mathrm{O}_{3}$ & $\mathrm{Na}_{2} \mathrm{O}$ & $\mathrm{CaO}$ & $\mathrm{TiO}_{2}$ & $\mathrm{Li}_{2} \mathrm{O}$ & LOI & Total \\
\hline Pyrophyllite & 61.57 & 29.91 & 0.26 & 0.27 & 0.18 & 0.69 & - & 6.94 & 99.82 \\
\hline Gibbsite & 0.01 & 66.09 & 0.01 & 0.21 & - & - & - & 33.60 & 99.92 \\
\hline Lithium carbonate & - & - & - & - & - & - & 40.00 & 59.00 & 99.00 \\
\hline
\end{tabular}

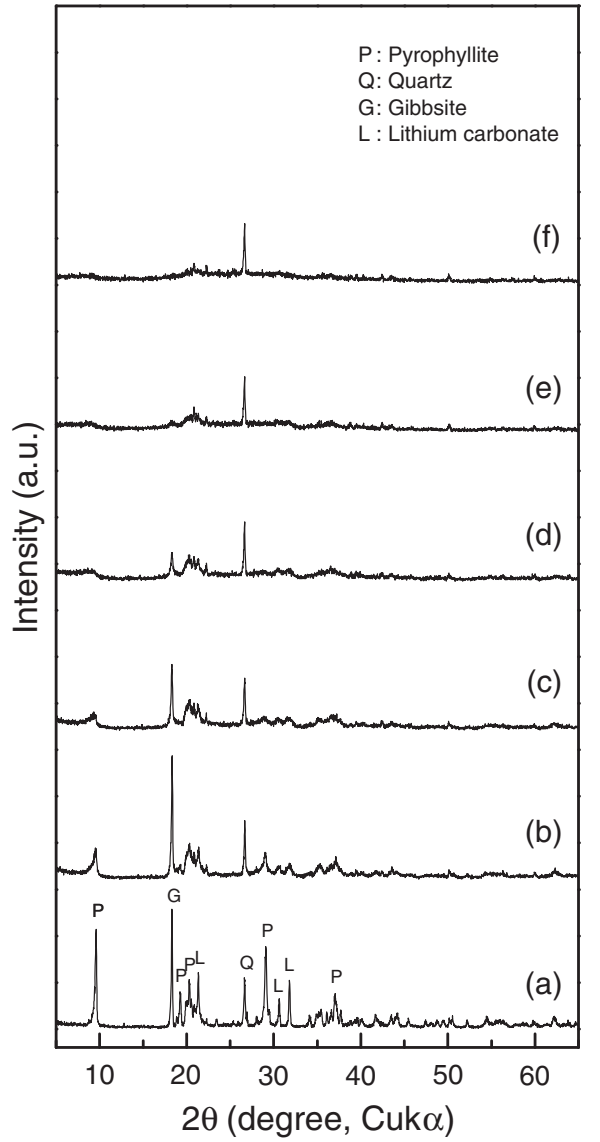

Fig. 1 XRD patterns of the mixture milled for various times, (a) unmilled, (b) $15 \mathrm{~min}$, (c) $30 \mathrm{~min}$, (d) $60 \mathrm{~min}$, (e) $90 \mathrm{~min}$ and (f) $120 \mathrm{~min}$ milling.

(DTG-60H, Shimazu). The infrared spectra of calcined powders were collected using an infrared spectrometry (Nicolet iS10, Thermo Scientific) and the morphology of the surface of calcined bodies were observed by scanning electron microscopy (SEM-4100, JEOL). For the determination of thermal expansion of calcined bodies, the pellet specimens with $5(\mathrm{~h}) \times 10(\phi) \mathrm{mm}$ were tested using a dilatometer (Q20, TA Instruments) heated at a rate of $3^{\circ} \mathrm{C} / \mathrm{min}$ in atmospheric condition.

\section{Results and Discussion}

Figure 1 shows the XRD patterns of the mixture milled for various times. The peak intensities of the starting materials reduced gradually as milling progressed. Except for quartz, the prolonged milling promoted the amorphization of the starting materials. Although very weak peaks of starting materials were detected in the sample milled for $90 \mathrm{~min}$, it can be assumed that the lattice structures of the starting materials

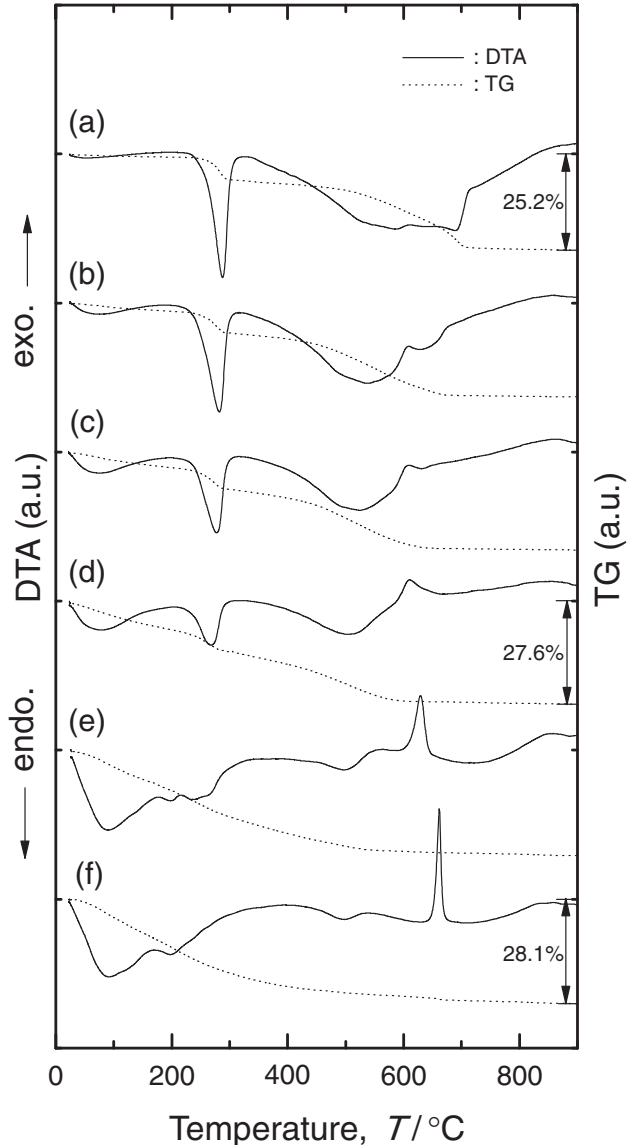

Fig. 2 TG-DTA curves of the mixture milled for various times, (a) unmilled, (b) $15 \mathrm{~min}$, (c) $30 \mathrm{~min}$, (d) $60 \mathrm{~min}$, (e) $90 \mathrm{~min}$ and (f) 120 min milling.

mostly became disordered at $90 \mathrm{~min}$. However, any mechanochemical solid-state reactions among the starting materials would not occur within the scope of this experiment.

Figure 2 shows the TG-DTA curves of the mixture milled for various times. In the curve of the unmilled mixture, three main endothermic peaks at around 290,600 and $700^{\circ} \mathrm{C}$ were detected and these peaks correspond to the dehydration of gibbsite $\left(290^{\circ} \mathrm{C}\right)$ and pyrophyllite $\left(600^{\circ} \mathrm{C}\right)$ and decarbonation of lithium carbonate $\left(700^{\circ} \mathrm{C}\right)$, respectively. The endothermic peak at around $290^{\circ} \mathrm{C}$ shifted slightly toward the lower temperature side by milling for $60 \mathrm{~min}$. Further milling resulted in the broad endothermic reaction under $200^{\circ} \mathrm{C}$ and the hydroxyl in gibbsite structure was believed to change into more loosely bonded hydroxyl and/or absorbed water. The endothermic peak at around $600^{\circ} \mathrm{C}$, corresponding to the formation of pyrophyllite dehydroxlate, shifted toward the lower temperature side with the progress of milling, supporting the structural change around the hydroxyl similar 

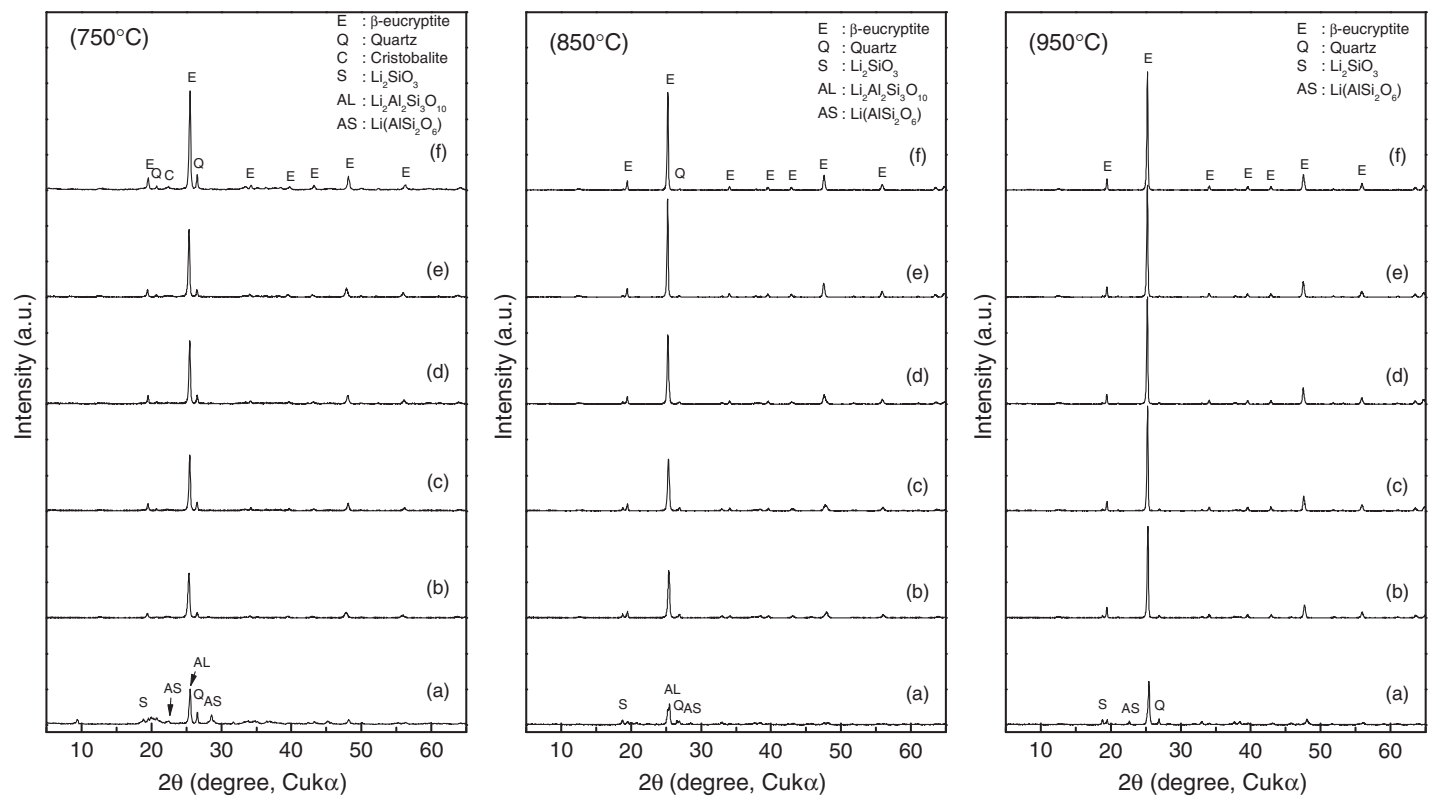

Fig. 3 XRD patterns of the mixtures calcined at various temperatures, (a) unmilled, (b) $15 \mathrm{~min}$, (c) $30 \mathrm{~min}$, (d) $60 \mathrm{~min}$, (e) $90 \mathrm{~min}$ and (f) 120 min milling.

to the case of gibbsite. ${ }^{9)}$ The exothermic peak at around $620^{\circ} \mathrm{C}$ for the crystallization of $\beta$-eucryptite in the curve of the mixture milled for $90 \mathrm{~min}$ was found to increase in its intensity and to shift to around $670^{\circ} \mathrm{C}$ with the increment of milling time to $120 \mathrm{~min}$. We could not give any definite explanation in this regard from the present results alone, however, such behavior appeared to be dependent on the various factors such as particle agglomeration and binding energy of constituent elements such as $\mathrm{Si}-\mathrm{O}-\mathrm{Al}$ linkage. ${ }^{10)} \mathrm{In}$ the case of weight loss curves accompanied by endothermic peaks, the value gradually increased as milling progressed. The noticeable change was mainly caused by the removal of hydroxyl groups in the milled material, especially in pyrophyllite, which adsorbed considerable amount of water molecule from the atmosphere during milling. This could be attributed to one of the origins of a broad endothermic reaction under $500^{\circ} \mathrm{C}$.

Figure 3 shows the XRD patterns of the mixtures calcined at various temperatures. At $750^{\circ} \mathrm{C}$, lithium silicate $\left(\mathrm{Li}_{2} \mathrm{SiO}_{3}\right)$, lithium aluminum silicate $\left(\mathrm{Li}_{2} \mathrm{Al}_{2} \mathrm{Si}_{3} \mathrm{O}_{10}\right.$ and $\left.\mathrm{Li}\left(\mathrm{AlSi}_{2} \mathrm{O}_{6}\right)\right)$ and quartz were the main crystalline phases developed in the original mixture. These peaks disappeared gradually and the peaks of $\beta$-eucryptite increased as milling progressed. $\beta$ eucryptite phase was formed as a major phase in the milled mixtures. However, the reflections of other minor associated phases such as cristobalite and quartz were also detected even though milling prolonged for $120 \mathrm{~min}$. The XRD profiles of the mixtures heat treated at different temperatures between 850 and $950^{\circ} \mathrm{C}$ showing the formation of $\beta$-eucryptite were also presented. It is apparent that the noticeable increase of $\beta$ eucryptite phase was observed with the temperature increase from 850 to $950^{\circ} \mathrm{C}$. The cristobalite $\left(750^{\circ} \mathrm{C}\right)$ and quartz $\left(850^{\circ} \mathrm{C}\right)$ phases retained in the mixtures almost disappeared and monolith $\beta$-eucryptite phase could be obtained in the mixture milled for $120 \mathrm{~min}$ at $950^{\circ} \mathrm{C}$. This indicates that $\beta$ eucryptite can be formed by mechanochemical activation. The reaction can be described as follows:



Fig. 4 FT-IR spectra of the (a) unmilled and (b) 120-min milled mixtures calcined at $950^{\circ} \mathrm{C}$.

$$
\begin{gathered}
\mathrm{Al}_{2} \mathrm{Si}_{4} \mathrm{O}_{10}(\mathrm{OH})_{2}+2 \mathrm{Al}(\mathrm{OH})_{3}+2 \mathrm{Li}_{2} \mathrm{CO}_{3} \\
\rightarrow 4 \mathrm{LiAlSiO}_{4}+2 \mathrm{CO}_{2}+4 \mathrm{H}_{2} \mathrm{O}
\end{gathered}
$$

In order to investigate the structural change occurred toward the formation of $\beta$-eucryptite, FT-IR spectra of the unmilled and 120-min milled mixtures calcined at $950^{\circ} \mathrm{C}$ were collected and presented in Fig. 4. The strong broad band in the wave number region around $1000 \mathrm{~cm}^{-1}$ indicated that the substitution of $\mathrm{Al}$ and $\mathrm{Si}$ took place within the $\mathrm{SiO}_{4}$ tetrahedra unit. ${ }^{11)}$ A sharp absorption band in the region $758 \mathrm{~cm}^{-1}$ appeared in the 120 -min milled mixture indicates the characteristic vibration of Al-O covalent bonding in $\mathrm{AlO}_{4}$ tetrahedra in $\beta$-eucryptite. ${ }^{12)}$ The absorption bands in the region 669 and $654 \mathrm{~cm}^{-1}$ were also the characteristic bands for $\beta$-eucryptite. ${ }^{13,14)}$

Figure 5 shows the dilatometric curves of the milled mixtures calcined at $950^{\circ} \mathrm{C}$. Table 2 listed the mean thermal 


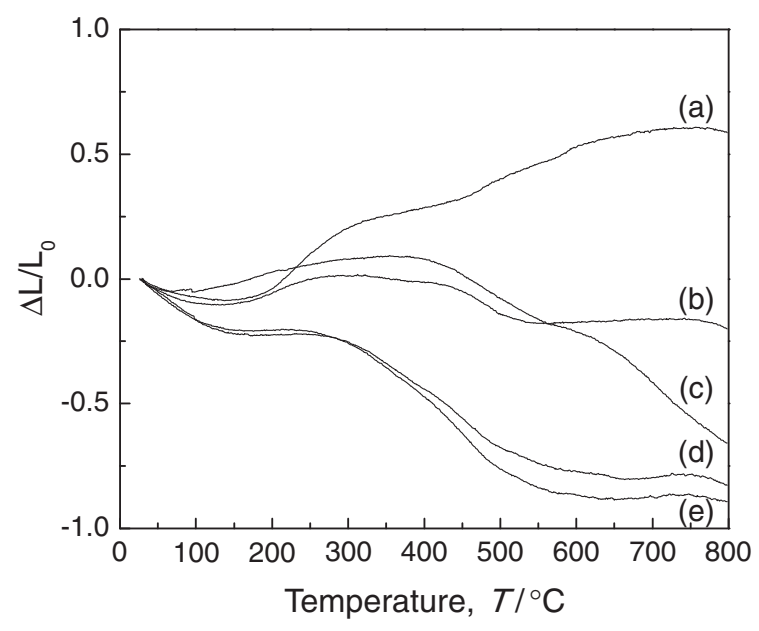

Fig. 5 Thermal expansion of the milled mixtures calcined at $950^{\circ} \mathrm{C}$, (a) $15 \mathrm{~min}$, (b) $30 \mathrm{~min}$, (c) $60 \mathrm{~min}$, (d) $90 \mathrm{~min}$ and (e) $120 \mathrm{~min}$ milling, $\Delta \mathrm{L} / \mathrm{L}_{0}=\left(\mathrm{L}-\mathrm{L}_{0}\right) / \mathrm{L}_{0}$ where $\mathrm{L}$ is the length of the specimen at certain temperature and $\mathrm{L}_{0}$ is the original length of the specimen at room temperature.

Table 2 Mean thermal expansion coefficient of the calcined specimens heated at $950^{\circ} \mathrm{C}$.

\begin{tabular}{ccccc}
\hline \multirow{2}{*}{$\begin{array}{c}\text { Specimen } \\
\text { (Milling time) }\end{array}$} & \multicolumn{4}{c}{ Mean TEC $\left(10^{-6} /{ }^{\circ} \mathrm{C}\right)$} \\
\cline { 2 - 5 } & $35-120^{\circ} \mathrm{C}$ & $150-250^{\circ} \mathrm{C}$ & $300-500^{\circ} \mathrm{C}$ & $450-750^{\circ} \mathrm{C}$ \\
\hline Unmilled & 4.575 & - & 5.699 & 5.468 \\
$15 \mathrm{~min}$ & -0.792 & 2.800 & 0.667 & 1.287 \\
$30 \mathrm{~min}$ & -1.427 & 1.006 & -1.674 & - \\
$60 \mathrm{~min}$ & - & 0.700 & - & -2.501 \\
$90 \mathrm{~min}$ & -2.214 & - & -2.158 & - \\
$120 \mathrm{~min}$ & -2.050 & - & -2.648 & - \\
\hline
\end{tabular}

expansion coefficient (TEC) over different temperature ranges. The linear expansion of the specimen prepared from the mixture milled for $15 \mathrm{~min}$ showed negative expansion from room temperature to $150^{\circ} \mathrm{C}$ followed by increasing to positive expansion as temperature increased. For the specimen from the mixtures milled for $30 \mathrm{~min}$, the linear expansion demonstrated complex variation tendency, where the thermal expansion decreased from room temperature to $800^{\circ} \mathrm{C}$ accompanied by several stages of decrease. The specimen milled for $60 \mathrm{~min}$ showed different linear expansion behavior. The curve indicated that the shrinkage proceeded gradually from 400 to $800^{\circ} \mathrm{C}$. The similar curves were obtained for the specimens from the mixtures milled for
90 and $120 \mathrm{~min}$, exhibiting two stage shrinkages over the temperature ranges from room temperature to $120^{\circ} \mathrm{C}$ and from 300 to $500^{\circ} \mathrm{C}$, respectively.

\section{Conclusions}

Monolith $\beta$-eucryptite was prepared by mechanochemical activation followed by calcination of the powder mixture containing pyrophyllite, gibbsite and lithium carbonate. XRD and FT-IR results showed that the crystallization of $\beta$ eucryptite occurred from the milled mixture by calcination. The crystallization of $\beta$-eucryptite increased with increment of milling time and calcination temperature. Trace amounts of cristobalite and quartz detected at $750^{\circ} \mathrm{C}$ decreased with increment of calcination temperature. Consequently, cristobalite disappeared completely at $850^{\circ} \mathrm{C}$ and quartz disappeared at $950^{\circ} \mathrm{C}$ in the mixture milled for $120 \mathrm{~min}$. The thermal expansion behavior characteristics were found to be strongly influenced by the milling time of the constituent powder mixture and calcination temperature.

\section{Acknowledgment}

This work was supported by the Korea Institute of Energy Technology Evaluation and Planning (KETEP) grant (No. 20112010300020) funded by the Korea government Ministry of Knowledge Economy (MKE).

\section{REFERENCES}

1) G. H. Beall: Annu. Rev. Mater. Sci. 22 (1992) 91-119.

2) A. I. Lichtenstein, R. O. Jones, S. De Gironcoli and S. Baroni: Phys. Rev. B 62 (2000) 11487-11493.

3) A. Jacobsen and T. Marx: Applications of the Glass-Ceramic Zerodur, in Low Thermal Expansion Glass-Ceramics, ed. by H. Bach, (SpringerVerlag, Berlin, Germany, 1995) p. 198.

4) L. Xia, G. Wen, L. Song and X. Wang: Mater. Chem. Phys. 119 (2010) 495-498.

5) W. F. Müller: J. Mater. Sci. 14 (1979) 1433-1439.

6) M. Chatterjee and M. K. Naskar: Ceram. Int. 32 (2006) 623-632.

7) S. Mandal, S. Chakrabarti, S. K. Das and S. Ghatak: Ceram. Int. 33 (2007) 123-132.

8) M. C. Wang, N. C. Wu, S. Yang and S. B. Wen: J. Mater. Res. 17 (2002) 1960-1968.

9) K. Sugiyama, J. M. Fillio, F. Saito and Y. Waseda: Mineral. J. 17 (1994) $28-41$.

10) K. Okada, N. Otsuka and J. Ossaka: Clay Sci. 6 (1987) 283-294.

11) M. K. Murthy and E. M. Lirby: J. Am. Ceram. Soc. 45 (1962) 324-329.

12) M. H. Lin and M. C. Wang: J. Mater. Sci. 30 (1995) 2716-2721.

13) N. N. Ghosh and P. Pramanik: Mater. Sci. Eng. B 49 (1997) 79-83.

14) B. N. Roy: J. Am. Ceram. Soc. 70 (1987) 183-192. 